\title{
Standardized patients versus simulated patients in medical education: are they the same or different
}

\author{
Amin Beigzadeh', Bahareh Bahmanbijari², Elham Sharifpoor ${ }^{3}$, Masoumeh Rahimi ${ }^{*}$ \\ ${ }^{1}$ Research Center for Health Services Management, Institute for Futures Studies in Health, Kerman University of Medical Sciences, \\ Kerman, Iran \\ ${ }^{2}$ Department of Pediatrics, Medical School, Kerman University of Medical Sciences, Kerman, Iran \\ ${ }^{3}$ Neurosciences Research Center, Institute of Neuropharmacology, Kerman University of Medical Sciences, Kerman, Iran \\ ${ }^{4}$ Department of Medical Education, Isfahan University of Medical Sciences, Isfahan, Iran
}

Received: 1 June 2015
Accepted: 7 July 2015
Published online: 15 September 2015
*Corresponding author:
Masoumeh Rahimi , Department of
Medical Education, Isfahan University
of Medical Sciences, Isfahan, Iran.
Email: m.rahimip@yahoo.com
Competing interests: None.
Funding information: None.
Citation: Beigzadeh A, Bahmanbijari B,
Sharifpoor E, Rahimi M. Standardized
patients versus simulated patients in
medical education: are they the same
or different. Journal of Emergency
Practice and Trauma 2016; 2 (1): $25-28$.
doi: 10.15171 jept.2015.05.

Received: 1 June 2015

Accepted: 7 July 2015

*Corresponding author:

Masoumeh Rahimi, Department of

Medical Education, Isfahan University

Email:m.rahimip@yahoo.com

Competing interests: None.

Funding information: None. patients versus simulated patients in

medical education: are they the same doi: $10.15171 /$ jept.2015.05

\begin{abstract}
In order to equip medical students with all the necessary skills in dealing with patients to provide optimal treatment, the need for the use of real patients in educational settings has become prominent. But all the required skills cannot be practiced on real patients due to patients' safety and well-being. Thus, the use of standardized patients (SPs) or simulated patients (SiPs) as a substitute for real patients signifies their importance in simulationbased medical education. One question raised in regard to using SPs or SiPs in order to enhance medical students' tangible and intangible skills in a safe controlled environment is whether these two terminologies are the same or different? Various studies use these terms interchangeably and do not consider a difference between them. Based on our literature review, there seems to be differences between these two modalities. We also try to highlight the advantages of these modalities in clinical encounters.

Keywords: Standardized patient; Simulated patient; Education, Medical
\end{abstract}

$\mathrm{P}$ erformance-based education can be described as an educational method to foster clinical skills as well as clinical knowledge of medical students. Studies show that performance-based methods are effective for teaching a whole gamut of knowledge, clinical skills, and attitudes $(1,2)$. There is a tendency towards performancebased teaching and assessment in medical education (3) and it has been highlighted by General Medical Council (GMC) and the Association of American Medical Schools. This can be achieved by early clinical practice which is necessary in both undergraduate and postgraduate medical education. In this regard, real patients as a resource for teaching a wide range of clinical communication and examination are inevitably precious. In respond to such necessity, it is important to provide more opportunities for medical students to practice in a safe and controlled environment to gain mastery over essential clinical skills and knowledge prior to entry in a real life clinical setting. Thus, the use of simulation has become widespread in many health professions. Simulation, an old phenomenon, is ubiquitous in almost every fields of human endeavor. It is commonplace in fields such as military, aviation, space, and nuclear power industry (4). But its pivotal role in the field of medical education is significantly prominent as doing critical procedural skills and physical examinations are risky to be conducted on real patients. Although, there are a continuum of teaching strategies that healthcare educators can adopt to teach medical students, but simulation is one of the best teaching strategies that has a significant impact on healthcare education to enhance clinical and professional skills and knowledge in a safe environment. But it should be contended that because of the changes in the health care system in terms of reduced inpatient beds, reduced length of hospital stay, and community based practice as well as concerns about validity and reliability of real patients in assessment, there has been a focus away from using real patients in the training of medical students (5). Thus, it was in 1960s that Barrows and Abrahamson (6) came up with the concept of standardized patients (SPs) and simulated patients (SiPs) as an alternative approach to using real patients in the training of medical students. So far, there seems to be confusion in the usage of these two terms among the research community in the reporting and description of performance- 
based simulation in terms of the terminology adopted. Thus, the purpose of this article is to investigate the literature to see whether a difference exists between these two terminologies. In addition, the advantages of these two modalities are highlighted.

\section{Definition of standardized patients (SPs) and simulated patients (SiPs)}

When conducting the literature review in order to find an exact definition for the terms standardized patients and simulated patients and distinguishing the differences between them, we were faced by a paucity of clear definitions in this perspective. Evidence shows that there are many papers that use the terms standardized patients and also a number that discuss simulated patients and do not consider a difference between them (7-9). This causes confusion among the healthcare educationists, researchers, and those in charge of developing simulations. Based on our review the following definitions seem to differentiate between these two terms:

Collins and Harden (10) define the term simulated patients as ordinary people who have received training to portray an amalgam of different clinical scenarios including history taking, physical examination, and communication skills. A simulated patient cannot be recognized and discerned by an expert if appropriately trained. Barrows (11) also provides the same definition for a simulated patient as a lay person (a normal person) who has been instructed carefully to be an actual patient in terms of presenting the signs and symptoms. On the other hand, the term standardized patients is defined as a lay person with or without his/her own medical problems (history and physical exam findings) or a real patient who has been coached to depict a specific medical case or play the role of a patient. In this case, real problems or those of other patients can be considered as the learning content (12). It seems that when we use the term simulated patients, we are more implicitly directing the participant towards the role of a patient or an acting role or a kind of role play. Based on the literature review by authors, we were not able to find any articles that specifically investigated the differences between these two terms except for an article by Churchouse and McCafferty (13) at Edith Cowan University, Perth, Western Australia. Based on their investigation, a simulated patient, directed by a facilitator, is a person who is given a history to portray and acts a role in the clinical encounter with a medical student. Conversely, a standardized patient is not an actor but a person who shows his or her personal, physical, social, and psychological history. So far, there seems to be differences between the terms standardized patients and simulated patients. Collins and Harden (10) and Barrows (11) express that the term 'standardized patient' is a broader term which covers both real and simulated patients and it does not indicate whether the patient being dealt with or discussed is a real or simulated one. The differences between a standardized patient and a simulated patient are shown in Table 1.

\section{Advantages of using standardized patients (SPs) and simulated patients (SiPs)}

One of the areas of concern is the clinical encounter between the patients and the medical students in which both tangible skills (procedural skills, physical examination) and intangible skills (communication skills, professional behavior, and interpersonal relationship) can be fostered. Typically, medical students are trained for this encounter by meeting real patients. However, for a couple of reasons such as the changes in the healthcare system and the validity and reliability of real patients in assessment, the use of real patients in educational settings has diminished in recent years. Other areas of attention can be related to the paucity of good educational cases. In addition, shortened clinical periods for the students at each department play a role here. We should not forget that ethically we cannot train medical students on real patients when ethical considerations are not taken into account (14). Thus, the simulated patients or standardized patients can be trained for a variety of clinical cases to respond more consistently in the training and examination of medical students than real patients. On the other hand, these modalities are more standardized for use in different centers and over a vast area internationally. When simulated patients or standardized patients are used, there would be a control over the learning content and the presentation or the clinical

Table 1. Comparison between standardized patients (SPs) and simulated patients (SiPs)

\begin{tabular}{ll}
\hline Standardized Patient (SP) & Simulated Patient (SiP) \\
\hline $\begin{array}{l}\text { A real patient who has been directed to use his/her own history and } \\
\text { physical exam findings to participate in the education of medical students }\end{array}$ & $\begin{array}{l}\text { A normal person who simulates a real patient based on varying } \\
\text { levels of training }\end{array}$ \\
$\begin{array}{ll}\text { A standardized patient is a person who is not an actor } & \text { A lay person who must be trained and coached carefully to play } \\
\text { the role of patients }\end{array}$ \\
$\begin{array}{l}\text { A standardized patient presents his/her real feelings e.g. emotional and } \\
\text { personality characteristics }\end{array}$ & $\begin{array}{l}\text { A simulated patient cannot be recognized by an expert clinician } \\
\begin{array}{l}\text { A standardized patient is a patient who has been briefed to play a patient } \\
\text { role }\end{array}\end{array}$ \\
$\begin{array}{l}\text { A standardized patient can be people with or without actual diseases } \\
\text { who have been trained to portray a medical case }\end{array}$ & $\begin{array}{l}\text { A simulated patient portrays various scenarios for the teaching } \\
\text { and assessment of history taking, communication skills or physical } \\
\text { examination where no abnormality is really present }\end{array}$ \\
\hline
\end{tabular}


scenarios can be repeated many times and are matched to the stage of training of the students. The availability of these modalities to real patients at an examination should also be taken into consideration especially where the use of a real patient would be inappropriate, e.g. counseling of a patient with cancer (10). When it comes to matters such as providing feedback to medical students, these modalities can highlight the student's strengths and weaknesses in a supportive way (15). Additionally, when medical students receive positive feedback regarding their performance in a clinical simulation encounter, their confidence not only in terms of their communication skills would be increased but also their anxiety level would be reduced. In this case, they can better implement the newly acquired skills. Repeated clinical exposure with simulated patients or standardized patients in a supportive environment has an apprehension-reducing effect. We should also bear in mind that when we encounter medical students with these modalities we are explicitly familiarizing them with this fact that patients have different experiences, ideas, beliefs, demeanor, and attitudes toward health care. Therefore, these modalities equip trainees with essential skills to interact with all types of patients, assess their needs, and provide relevant information and interventions (16). One of the most important advantages of simulated patients and standardized patients is their use in exchanging information about disease complications and prognosis. This information can be freely discussed in a clinical encounter with these modalities. This ensures that medical students can practice examination techniques as many times as possible without feeling ashamed if they were supposed to practice these skills on real patients. We can also be on the safe side of the margin feeling at ease that medical students do not exhaust or hurt a real patient but a simulated patient or a standardized patient (17).

Due to the versatility of simulation instruments especially in the area of using standardized patients and simulated patients instead of real patients in clinical encounters, it is recommended that educators and clinical instructors pay more attention to the application of SPs and SiPs. It is important to notice that standardized patients or simulated patients should not only be approached due to the educational problems that are inherited with real patients in clinical encounters but also they are invaluable in the education and assessment processes. We also believe that these modalities should be used based on the required clinical skills and competencies within the medical curriculum. This highlights that a careful planning regarding the use of standardized patients and simulated patients into the medical curriculum needs to be considered as comprehensively as possible so that the most suitable and competent doctors will deliver health care services to the community upon graduation.

\section{Ethical issues}

Not applicable.

\section{Authors' contributions}

All authors equally contributed to the writing and revision of this paper.

\section{References}

1. Harden RM, Gleeson FA. Assessment of clinical competence using an objective structured clinical examination (OSCE). Med Educ 1979; 13(1): 41-54. doi: 10.1111/j.1365-2923.1979.tb00918.x.

2. Robb KV, Rothman A. The assessment of historytaking and physical examination skills in general internal medicine residents using a checklist. Ann Royal Coll Phys Surg Canada 1985; 20: 45-8.

3. Collet JH, Ress JA, Mylrea S, Crowther I. Performance based assessment in pharmacy education. Int J Pharm Pract 1994; 3: 38-41.

4. Bradley P. The history of simulation in medical education and possible future directions. Med Educ 2006; 40(3): 254-62. doi: 10.1111/j.13652929.2006.02394.x

5. Cleland JA, Abe K, Rethans JJ. The use of simulated patients in medical education: AMEE Guide No 42. Med Teach 2009; 31(6): 477-86. doi: 10.1080/01421590903002821.

6. Barrows HS, Abrahamson S. The programmed patient: a technique for appraising student performance in clinical neurology. J Med Educ1964; 39(8): 802-5.

7. Bosek MS, Li S, Hicks FD. Working with standardized patients: a primer. Int J Nurs Educ Scholarsh 2007; 4(1): 1-13.

8. Boulet JR, Smee SM, Dillon GF, Gimpel JR. The use of standardized patient assessments for certification and licensure decisions. Simul Healthc 2009; 4(1): 35-42. doi: 10.1097/sih.0b013e318182fc6c.

9. Lane JL, Slavin S, Ziv A. Simulation in medical education: a review. Simul Gaming 2001; 32(3): 297 314. doi: 10.1177/104687810103200302.

10. Collins J, Harden R. The use of real patients, simulated patients and simulators in clinical examinations 2004. Association for Medical Education in Europe (AMEE) Guide No 13. Available from: http://78.158.56.101/ archive/MEDEV/static/uploads/resources/amee_ summaries/Guide13summaryMay04.pdf

11. Barrows HS. An overview of the uses of standardized patients for teaching and evaluating clinical skills. AAMC. Acad Med 1993; 68(6): 443-51. doi: 10.1097/00001888-199306000-00002

12. Barrows HS, Cohen R, Guerin RO, Hart IR, Klass DJ, Kopelow $\mathrm{M}$, et al. Consensus statement of the researchers in clinical skills assessment (RCSA) on the use of standardized patients to evaluate clinical skills. Acad Med 1993; 68(6): 475-7.

13. Churchouse C, McCafferty C. Standardized patients versus simulated patients: is there a difference? Clinical Simulation in Nursing 2012; 8(8): e363-5. doi: 10.1016/j.ecns.2011.04.008 
14. Bergin RA, Fors UG. Interactive simulated patientan advanced tool for student-activated learning in medicine and healthcare. Comput Educ 2003; 40(4): 361-76. doi: 10.1016/s0360-1315(02)00167-7.

15. Lane $C$, Rollnick S. The use of simulated patients and role-play in communication skills training: a review of the literature to August 2005. Patient Educ Couns 2007; 67(1-2): 13-20. doi: 10.1016/j.pec.2007.02.011.
16. Mesquita AR, Lyra DP, Brito GC, Balisa-Rocha BJ, Aguiar PM, de Almeida Neto AC. Developing communication skills in pharmacy: a systematic review of the use of simulated patient methods. Patient Educ Couns 2010; 78(2): 143-8. doi: 10.1016/j. pec.2009.07.012

17. Barrows H. Simulated patients in medical teaching. Can Med Assoc J 1968; 98(14): 674-6. 